\title{
Genomic evaluation for calf wellness traits in Holstein cattle
}

\author{
D. Gonzalez-Peña, N. Vukasinovic, ${ }^{*}$ J. J. Brooker, C. A. Przybyla, and S. K. DeNise \\ Zoetis Genetics, Kalamazoo, Ml 49007
}

\section{ABSTRACT}

Reducing calf morbidity and mortality is important for attaining financial sustainability and improving animal welfare on commercial dairy operations. Zoetis (Kalamazoo, MI) has developed genomic predictions for calf wellness traits in Holsteins that include calf respiratory disease (RESP; recorded between 0 and 365 d of age), calf scours (DIAR; recorded between 2 and 50 $\mathrm{d}$ of age), and calf livability (DEAD; recorded between 2 and $365 \mathrm{~d}$ of age). Phenotype and pedigree data were from commercial dairies and provided directly by producers upon obtaining their permission. The number of records ranged from 741,484 for DIAR to 1,926,261 for DEAD. The number of genotyped animals was 325,025 . All traits were analyzed using a univariate threshold animal model including fixed effect of year of birth $\times$ calving season $\times$ region, and random effects of herd $\times$ year of birth and animal. A total of 45,425 SNP were used in genomic analyses. Animals genotyped with low-density chips were imputed to the required number of SNP. All analyses were conducted using single-step genomic BLUP implementing the "algorithm for proven and young" (APY) animals designed to accommodate very large numbers of genotypes. Estimated heritabilities were 0.042, 0.045, and 0.060 for RESP, DIAR, and DEAD, respectively. The genomic predicted transmitting abilities ranged between -8.0 and $24.0,-11.5$ and 28.5, and -6.5 to 22.8 for RESP, DIAR, and DEAD, respectively. Reliabilities of breeding values were obtained by approximation based on partitioning of a function of reliability into contributions from records, pedigree, and genotypes, where the genotype contribution was approximated using the diagonal value of the genomic relationship matrix. The average reliabilities for the genotyped animals were 41.9, 42.6, and $47.3 \%$ for RESP, DIAR, and DEAD, respectively. Estimated genomic predicted transmitting abilities and reliabilities were approximately normally distributed for all analyzed traits. Approximated genetic correlations of calf wellness with Zoetis dairy wellness traits and traits

Received August 10, 2018.

Accepted November 12, 2018.

*Corresponding author: natascha.vukasinovic@zoetis.com included in the US national genetic evaluation were low to moderate. The results indicate that direct evaluation of calf wellness traits under a genomic threshold model is feasible and offers predictions with average reliabilities comparable to other lowly heritable traits. Genetic selection for calf wellness traits presents a compelling opportunity for dairy producers to help manage herd replacement costs and improve overall profitability.

Key words: calf wellness, respiratory disease, scours, calf livability, genomic predictions

\section{INTRODUCTION}

Replacement costs are one of the largest financial components on a dairy farm. Costs of raising a calf from birth to first calving have been estimated at $\$ 1,200$ to over $\$ 2,000$ (Rossini, 2004). A heifer that experiences a disease at least once has $6 \%$ higher rearing costs than a healthy heifer (Mohd Nor et al., 2012). Therefore, keeping calves healthy and minimizing mortality and morbidity are key investments with real future returns that may mean the difference between profit or loss in tight margin years. In a study by Sischo et al. (1990), calf disease costs represented $4 \%$ of the total cost a cow incurred during her lifetime. Diarrhea and pneumonia were responsible for $86 \%$ of calf disease costs. In spite of improved management and calf-rearing practices, preweaning death loss in dairy calves range from 7.8 to $12 \% ; 53 \%$ of those losses are due to digestive problems (scours) and 21\% to respiratory diseases (Murray, 2011). Even if the calf survives and recovers from the disease, its performance as a mature cow will be affected. Occurrence of a calfhood disease increases the age at first calving by up to 2 mo, reduces survival through the first and second lactations, and increases culling due to mastitis and other diseases (Rossini, 2004).

Producing calves that are robust and able to thrive under the challenges of modern dairy operations is essential for both the economics of the dairy industry and the welfare of the animals (Gulliksen et al., 2009). In addition to improving herd management practices, increasing calf disease resistance genetically is essential for the success of dairy operations. Using genetic selection as a tool to improve calf wellness in dairy herds has been researched but, so far, not implemented. The only 
Table 1. Calf wellness trait definitions and characteristics of the data

\begin{tabular}{|c|c|c|c|c|c|c|c|c|}
\hline Trait & Acronym & Description & Records & $\begin{array}{c}\text { Incidence } \\
(\%)\end{array}$ & $\begin{array}{l}\text { No. of } \\
\text { herds }\end{array}$ & $\begin{array}{c}\text { Average } \\
\text { herd size }^{1}\end{array}$ & $\mathrm{G}+\mathrm{P}^{2}$ & Pedigree $^{3}$ \\
\hline Calf respiratory disease & RESP & RESP + PNEU $^{4} 0-365 \mathrm{~d}$ of age & $1,331,626$ & 21.0 & 188 & 7,083 & 67,289 & $2,310,723$ \\
\hline Calf scours & DIAR & DIAR $2-50 \mathrm{~d}$ of age & 741,484 & 26.1 & 118 & 6,283 & 70,275 & $1,583,960$ \\
\hline
\end{tabular}

${ }^{1}$ Average number of phenotypic records per herd across all years of data.

${ }^{2}$ Number of animals with a genotype that also had a phenotype for each trait.

${ }^{3}$ Number of animals in the final pedigree for each trait.

${ }^{4}$ Pneumonia.

traits available in dairy genetic evaluations focusing on characteristics of the calf are stillbirth in the United States and calf survival in Canada (Henderson et al., 2011). Several studies based on limited numbers of animals have indicated that calf health and survival are genetically controlled and that the genetic component, although small, can be successfully exploited in breeding programs. Most heritability estimates for calf respiratory diseases were low, ranging from 0.04 in Holstein calves in Ontario (McCorquodale et al., 2013) to 0.05 in Norwegian Red calves (Heringstad et al., 2008) to 0.09 in Holstein calves in New York (Henderson et al., 2011), and up to 0.21 when estimated using a genomic relationship matrix (Neibergs et al., 2014). Similar heritabilities were obtained for scours, bloat, and other digestive diseases in dairy calves (Henderson et al., 2011; McCorquodale et al., 2013). Heritability estimates for calf mortality (or survival) have been lower, ranging from 0.001 to 0.008 in Danish Holsteins (Hansen et al., 2003) and 0.004 for a "heifer livability" trait currently researched by USDA scientists (Norman, 2016).

Another obstacle in implementing genetic evaluations for calf health is the lack of routinely recorded data. Dairy farms, including calf-raising facilities, usually record calf health events and treatment using their herd management software, but many factors influencing calf health and survival, such as birth weight, amount of colostrum fed, blood protein level, and so on, are not routinely measured and recorded. However, previous studies have shown that producer-recorded data, albeit imperfect, can be successfully used in genomic evaluations of dairy cow wellness traits (e.g., Zwald et al., 2004; Parker Gaddis et al., 2014; Vukasinovic et al., 2017). The inclusion of genomic data substantially improves reliabilities for these traits (Parker Gaddis et al., 2014; Vukasinovic et al., 2017).

The objectives of this study were to explore the genetic background of calf wellness traits, to develop a system for genomic evaluation for those traits in Holstein dairy calves based on producer-recorded data, and to estimate genetic correlations among calf wellness traits and traits in the national dairy genetic evalu- ation as well as Zoetis dairy wellness traits (Zoetis, Kalamazoo, MI).

\section{MATERIALS AND METHODS}

\section{Phenotype Data}

Phenotype data were obtained directly from dairy producers upon obtaining their permission. As of March 2018, data from 326 herds located in 24 US states was available. The characteristics of the data are shown in Table 1.

Backup files produced using herd management software were delivered to Zoetis, opened, and processed using internally written scripts. Initially, all events up to 1 yr of age were extracted to "format $\mathrm{CH}$ files," files identical in format to the standard USDA format 6 (https://redmine.uscdcb.com/projects/cdcb-customer -service/wiki/Format_6). As of March 2018, a total of $3,288,342$ events recorded during the first year of life were available. Pedigree information was extracted from the backup files.

Out of the events typically occurring at young age, respiratory problems (RESP), pneumonia (PNEU), scours/diarrhea (DIAR), and mortality (DEAD) were chosen for further analyses. Umbilical hernias or bloat, although important calf health traits, were not considered because too few records were available. Further, respiratory events (RESP and PNEU) were merged into RESP because some herds recorded only "RESP," some only "PNEU," and some both.

Trait Definition. The incidence of calf health disorder was plotted against the age when a certain calf health event was first recorded. Distributions of RESP/ PNEU, DIAR, and DEAD events by age from 0 to 365 $\mathrm{d}$ are given in Figures 1, 2, and 3, respectively.

The distribution of respiratory diseases shows 4 distinct peaks: the first, and highest, occurs very shortly after birth, likely due to aspiration pneumonia (Poulsen and McGuirk, 2009); the second peak occurs during the first week of life; the third peak happens around 35 $\mathrm{d}$ of age, and the fourth, and largest, occurs between 


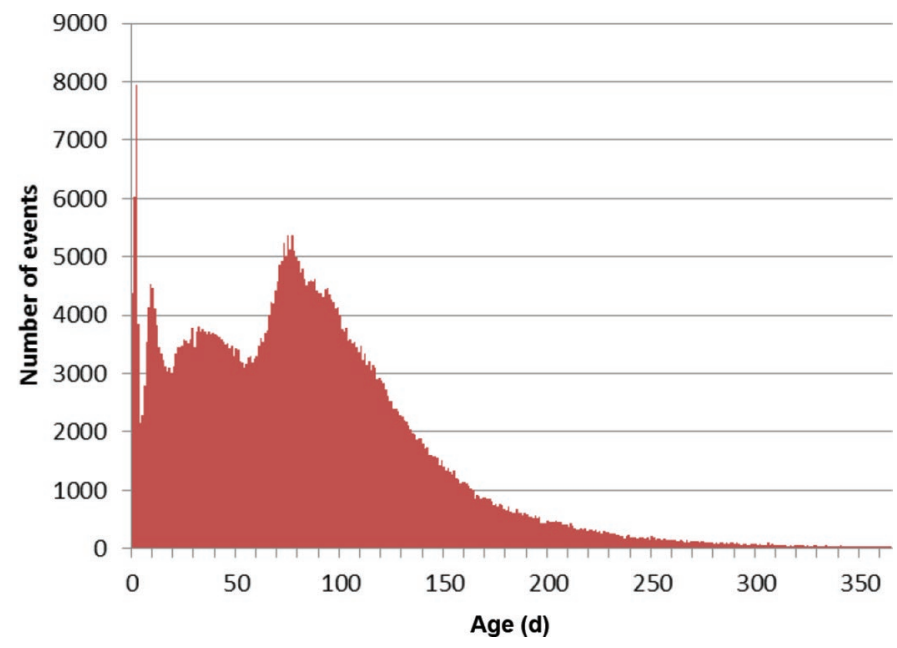

Figure 1. Distribution of calf respiratory disorders, including pneumonia, by age.

about 60 and $100 \mathrm{~d}$ of age, and is most likely caused by moving animals from individual housing to group pens (Hulbert and Moisá, 2016). After that, the incidence of respiratory diseases gradually decreases up to $365 \mathrm{~d}$. Incidence of scours or diarrhea peaks at about $10 \mathrm{~d}$ of age and reduces sharply after that. Mortality is high during the first $2 \mathrm{~d}$ of life, and again around 7 to $10 \mathrm{~d}$, after which it gradually decreases.

To cover the time periods when the respiratory disease, scours, and death are most likely to happen in young animals and have most economic impact, the traits for further analysis were defined as shown in Table 1.

Calf respiratory disease (RESP) was defined to cover the entire period from 0 to $365 \mathrm{~d}$ of age. Calf scours (DIAR) was limited to the range of 2 to $50 \mathrm{~d}$ of age, because after that, the incidence of scours was negli-

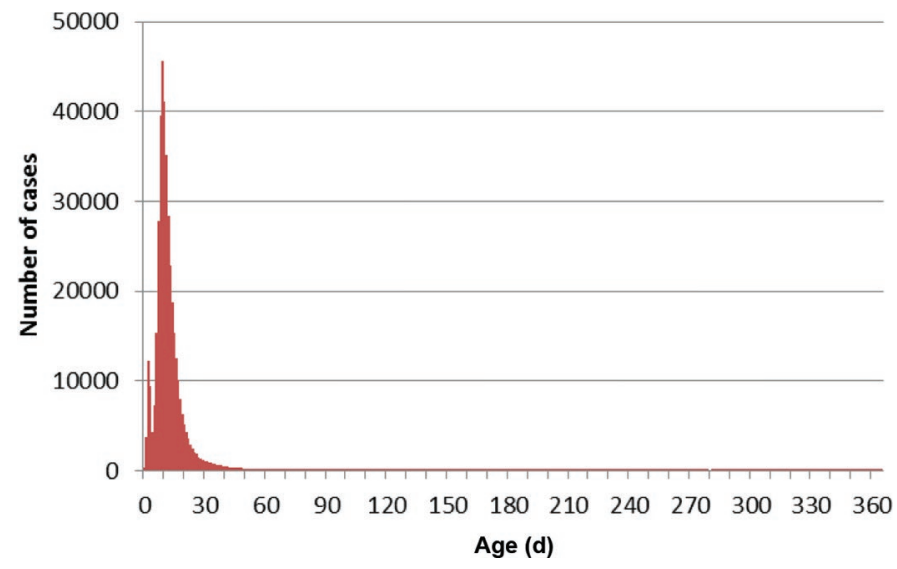

Figure 2. Distribution of scours by age. gible. Calf livability (DEAD) was defined to describe all mortality cases recorded between 2 and $365 \mathrm{~d}$ of age (the first $2 \mathrm{~d}$ of life were omitted to avoid confounding early deaths with stillbirth).

Data Editing. The information from the $\mathrm{CH}$ files (health events for calves) was merged with the pedigree information to include all healthy herdmates of the affected animals. "Healthy" animals were defined as animals not recorded for a particular trait. All traits were treated as binary events, having a value of 1 if the animal was recorded as having a disorder (or died) and 0 otherwise.

All animals having the event "SOLD" in the first week of life as the only event were removed from the data. All male calves, as well as animals with events recorded before their birth date, were removed. Records were also removed for all animals (healthy and sick) that did not reach the opportunity period, which was defined as the upper age limit for each trait and calculated as the number of days between the birth and the date when the farm backup file was created. At this point, all nonHolstein calves were also removed.

Finally, for each trait, herd $\times$ year groups with fewer than 10 records were removed. Also removed were herd $\times$ year groups with the incidence of disorder being $<0.5 \%$ or $>95 \%$ to avoid underreporting or matching cases with insufficient number of healthy herdmates. The final numbers of animals and records for each trait with phenotypes and average incidence are in Table 1.

\section{Genotype Data}

Animals from commercial herds submitted to Zoetis for genomic testing were genotyped with various versions of low-density and medium-density chips. Raw genotypes were edited following the criteria described in

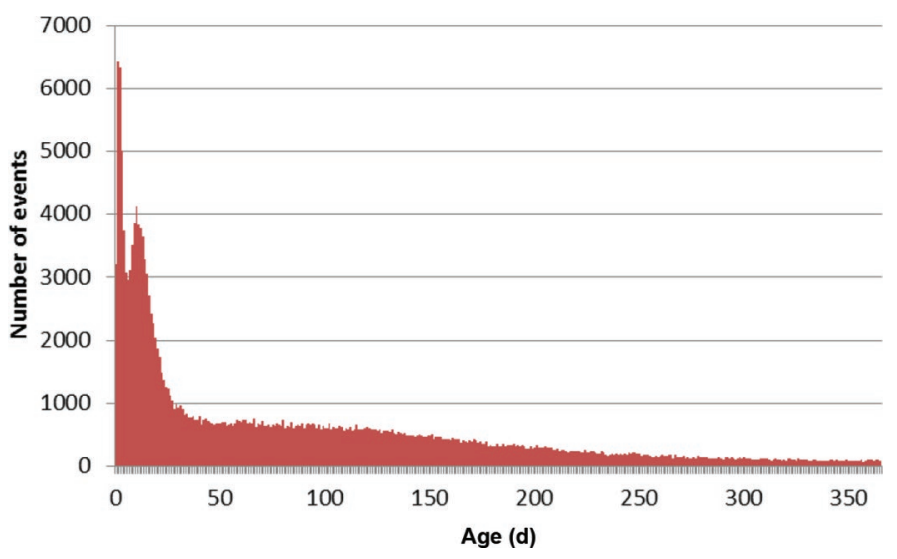

Figure 3. Distribution of calf mortality by age. 
Wiggans et al. (2009) and Vukasinovic et al. (2017). All animals genotyped with lower density chips $(<40,000$ markers) were imputed to 45,425 markers using the program FImpute (Sargolzaei et al., 2011). A total of 325,025 genotyped animals from herds that provided permission to Zoetis to use their data for research and development purposes were included in the analyses (Table 1).

\section{Statistical Model}

Each trait was analyzed separately, using the following univariate threshold animal model:

$$
\boldsymbol{\lambda}=\mathbf{X} \boldsymbol{\beta}+\mathbf{Z}_{\mathrm{h}} \mathbf{h}+\mathbf{Z}_{\mathrm{a}} \mathbf{a}+\mathbf{e},
$$

where $\boldsymbol{\lambda}$ represents a vector of the animals' unobserved liabilities to the given disorder; $\boldsymbol{\beta}$ is the vector of fixed effects of year $\times$ season of birth $\times$ region combination [years 1996 to 2017 were considered; 4 birth seasons were defined within each year: Winter (Dec-Feb), Spring (Mar-May), Summer (Jun-Aug), and Fall (SepNov); and 5 geographical regions based on climate were defined as in VanRaden et al. (2004)]; $\mathbf{h}$ is the random herd-year effect, where $\mathbf{h} \sim N\left(0, \mathbf{I} \sigma_{h}^{2}\right)$, with variance $\sigma_{h}^{2}$; $\mathbf{I}$ is the identity matrix; $\mathbf{a}$ is the random animal effect, with $\mathbf{a} \sim N\left(0, \mathbf{H} \sigma_{a}^{2}\right)$, where $\sigma_{a}^{2}$ is the additive genetic variance and $\mathbf{H}$ is the pedigree relationship matrix augmented using genotypes; $\mathbf{X}, \mathbf{Z}_{\mathrm{h}}$, and $\mathbf{Z}_{\mathrm{a}}$ are incidence matrices corresponding to the fixed effects in $\boldsymbol{\beta}$ and the random effects of herd $\times$ year and animal, respectively; and $\mathbf{e}$ is the residual.

\section{Variance Component Estimation}

Variance components for calf wellness traits were estimated using the same model but, for simplicity, without genomic information. Previous studies have shown that differences between values of heritabilities estimated with and without including markers were not relevant (e.g., Parker Gaddis et al., 2014; Gonzalez-Pena et al., 2018). The variance components were estimated using ASReml version 4.1 (Gilmour et al., 2015), using the REML methodology. All binary traits were analyzed using generalized linear models with a binomial distribution and a link function of LOGIT where the residual variance on the underlying scale equals $1 / 3 \pi^{2}$. Because the threshold model in the BLUPF90 program requires residual variance to be 1 , the variance components estimated by ASReml using the binomial model with the logit link function were adjusted to the residual variance of 1.00 by dividing each component by 3.29 , so that their ratios remained the same. Heritabilities and their standard errors were estimated using the "pin" function in ASReml, and the formula $\operatorname{Var}(\mathrm{g}) /[\operatorname{Var}(\mathrm{g})+$ $\operatorname{Var}($ hy) + $\operatorname{Var}(\mathrm{e})]$, where $\operatorname{Var}(\mathrm{g})$ and $\operatorname{Var}($ hy) represent additive genetic and herd-year variances, respectively, and $\operatorname{Var}(\mathrm{e})$ equals $1 / 3 \pi^{2}$ or 3.29 .

Before using ASReml software, we attempted to implement the threshold model in the program "thrgibbsf90", but it showed convergence problems, and some parameters were out of range when different options were tried for the model (data not shown), probably because of a large number of levels of the fixed effect of year $\times$ season $\times$ region (Misztal, 2005).

\section{Genomic Evaluation}

Genomic evaluation was performed using the programs from the BLUPF90 family (Misztal et al., 2002). A univariate threshold animal model based on singlestep genomic BLUP methodology (ssGBLUP) was applied to all traits. In ssGBLUP, the inverse of the traditional pedigree relationship matrix, $\mathbf{A}^{-1}$, is replaced by the inverse of the $\mathbf{H}$ matrix that combines pedigree and genomic relationships (Legarra et al., 2009; Aguilar et al., 2010):

$$
\mathbf{H}^{-1}=\mathbf{A}^{-1}+\left[\begin{array}{cc}
0 & 0 \\
0 & \left(\tau \mathbf{G}^{-1}-\omega \mathbf{A}_{22}^{-1}\right)
\end{array}\right],
$$

where $\mathbf{A}^{-1}$ is an inverse of the pedigree relationship matrix, $\mathbf{G}^{-1}$ is an inverse of the genomic relationship matrix (VanRaden, 2008), $\mathbf{A}_{22}^{-1}$ is an inverse of the pedigree relationship matrix for genotyped animals only, and $\tau$ and $\omega$ are scaling factors to condition the genomic relationship matrix to be compatible with the pedigree information that were both set to 1.0 (Misztal et al., 2010, 2013). To accommodate the large number of genotypes, the algorithm for proven and young animals (APY) was applied (Misztal et al., 2014a). The APY algorithm generates $\mathbf{G}^{-1}$ using genomic recursion based on a subset of animals ("proven" or "core" animals). Only a relationship matrix for animals defined as "core" needs to be inverted; elements of $\mathbf{G}^{-1}$ for all other animals ("young" or "non-core") are calculated linearly by recursion, thus reducing computational requirements. Computational details of APY are described in Fragomeni et al. (2015) and Masuda et al. (2016). The program "cblup90iod2" (version 3.21; Misztal et al., 2014b) was used to obtain genomic breeding values by iteration on data using preconditioned conjugate gradient. The core consisted of 25,000 randomly selected animals. The core size was determined through 
Table 2. Estimated variance components ${ }^{1}$ for calf wellness traits, heritabilities, and their standard errors, from the ASReml analysis with binomial distribution and a LOGIT link function

\begin{tabular}{lccccccc}
\hline Trait $^{2}$ & $\operatorname{Var}(\mathrm{g})$ & $\operatorname{Var}(\mathrm{hy})$ & $\operatorname{Var}(\mathrm{e})$ & $\mathrm{h}^{2}$ & $\mathrm{SE}\left(\mathrm{h}^{2}\right)$ & $\operatorname{Var}(\mathrm{g}) \operatorname{adj}$ & $\operatorname{Var}(\mathrm{hy}) \operatorname{adj}$ \\
\hline RESP & 0.251 & 2.436 & 3.29 & 0.042 & 0.002 & 0.076 & 0.740 \\
DIAR & 0.305 & 3.133 & 3.29 & 0.045 & 0.002 & 0.093 & 0.952 \\
DEAD & 0.308 & 1.540 & 3.29 & 0.060 & 0.003 & 0.094 & 0.468 \\
\hline
\end{tabular}

${ }^{1} \operatorname{Var}(\mathrm{g})=$ additive genetic variance; $\operatorname{Var}(\mathrm{hy})=$ herd-year variance; $\operatorname{Var}(\mathrm{e})=$ residual variance; $\mathrm{SE}\left(\mathrm{h}^{2}\right)=\mathrm{SE}$ of the heritability; $\operatorname{Var}(\mathrm{g})$ adj, $\operatorname{Var}($ hy $)$ adj, $\operatorname{Var}(\mathrm{e})$ adj = variance components adjusted to $\operatorname{Var}(\mathrm{e})=1$ to fit the requirements of the threshold model in BLUPF90 programs. Adjusted values show the actual values used in BLUPF90 programs for genetic evaluation.

${ }^{2} \mathrm{RESP}=$ calf respiratory disease; DIAR $=$ calf scours $; \mathrm{DEAD}=$ calf livability.

eigenvalue decomposition of the genomic relationship matrix and the numbers of largest eigenvalues explaining $99 \%$ of the variation were selected (Pocrnic et al., 2016) as implemented in the program "preGSF90" (version 1.10; Aguilar et al., 2014; Daniela Lourenco, Department of Animal and Dairy Science, University of Georgia, Athens, personal communication, 2017). The parameters determining the relative contribution of the genomic variance versus the residual polygenic variance (also known as $\alpha$ and $\beta$ parameters) were set to 0.95 and 0.05 , respectively. The preconditioned conjugate gradient method was run until the convergence criteria reached the threshold of $1 \times 10^{-12}$. Inbreeding was considered when constructing a pedigree relationship matrix with a depth of 20 generations (or the maximum number of generations available for each animal). The reliabilities of EBV were obtained with the program "accf90GS" (version 2.42), which approximates reliabilities using contributions from genotypes, phenotypes, and pedigree (Tsuruta et al., 2016). To reduce computational requirements, the contribution from genotypes is replaced by the value of the diagonal of the $\mathbf{G}$ matrix, $g_{i i}$. The following formula was used to approximate reliabilities for genotyped animals (Daniela Lourenco, personal communication, 2016):

$$
d_{i}^{g}=\alpha \times\left[\left(\overline{R E L}+g_{i i}\right)+\overline{R e l-R e l_{P A}}\right],
$$

where $d_{i}^{g}$ is the reliability of (genomic) EBV for animal $i, \alpha$ is the ratio of error variance to additive genetic

Table 3. Mean, SD, minima, and maxima of estimated genomic PTA for calf wellness traits for genotyped animals with values of the diagonal of the genomic relationship matrix (G_diag) within $\pm 3 \mathrm{SD}$ from the mean $(\mathrm{n}=321,532)$

\begin{tabular}{lcccc}
\hline Trait $^{1}$ & Mean & SD & Minima & Maxima \\
\hline RESP & 2.715 & 3.398 & -8.00 & 24.007 \\
DIAR & 1.229 & 3.720 & -11.510 & 28.515 \\
DEAD & 0.499 & 2.226 & -6.473 & 22.797 \\
\hline
\end{tabular}

${ }^{1} \mathrm{RESP}=$ calf respiratory disease; DIAR $=$ calf scours; DEAD $=$ calf livability. variance, $g_{i i}$ is the diagonal element of the genomic relationship matrix pertinent to animal $i, \overline{R E L}$ is the average base change in genomic reliability, and $\overline{R e l-R e l_{P A}}$ is the contribution from phenotypes of genotyped animals. Thus, reliabilities were adjusted for the number of genotyped animals having phenotypes. All calculations were performed on a computer running Linux (x86_64) RedHat release 7.3 with Intel Xeon E5-4620 CPU $(2.6 \mathrm{GHz})$ processors with $1 \mathrm{~TB}$ memory and 64 computing cores.

\section{Expression of EBV}

For each trait, the solutions from the "cblup90iod2" program (raw EBV) were transformed into probabilities of exceeding the threshold value. The threshold represents the transition value between the 2 stages of the categorical variable ("healthy" and "sick"). Threshold values for all traits were calculated from the current data. For each animal solution, we calculated the probability that a standard normal variable with the mean equal to this solution and the variance of 1 exceeds the threshold. The probabilities were then multiplied by 100 (to represent percent) and divided by 2 (to obtain PTA). Animals with larger PTA values have higher relative disease risk compared with herdmates with smaller PTA values. Similar to Zoetis dairy wellness traits (Vukasinovic et al., 2017), the resulting PTA values were expressed as the deviation of the average PTA of all animals born in 2010 with a phenotypic record for that trait.

Table 4. Mean, SD, minima, and maxima of genomic reliabilities for calf wellness traits for genotyped animals with values of the diagonal of the genomic relationship matrix (G_diag) within \pm 3 SD from the mean $(\mathrm{n}=321,532)$

\begin{tabular}{lcccc}
\hline Trait $^{1}$ & Mean & SD & Minima & Maxima \\
\hline RESP & 0.419 & 0.061 & 0.189 & 0.99 \\
DIAR & 0.426 & 0.061 & 0.203 & 0.99 \\
DEAD & 0.473 & 0.056 & 0.246 & 0.99 \\
\hline
\end{tabular}

${ }^{1} \mathrm{RESP}=$ calf respiratory disease; DIAR $=$ calf scours $;$ DEAD $=$ calf livability. 
a)

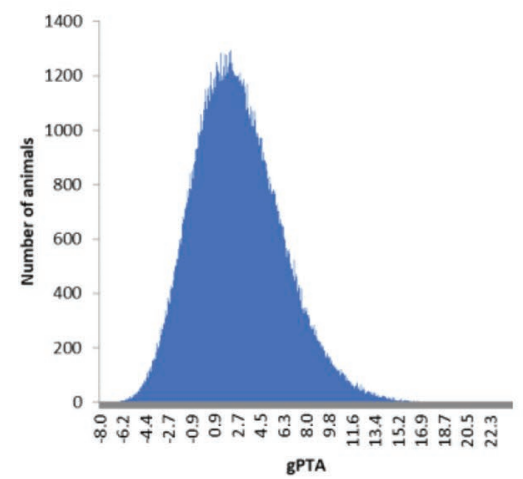

b)

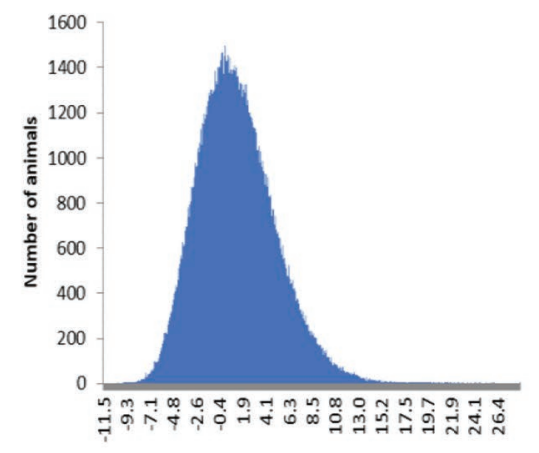

c)

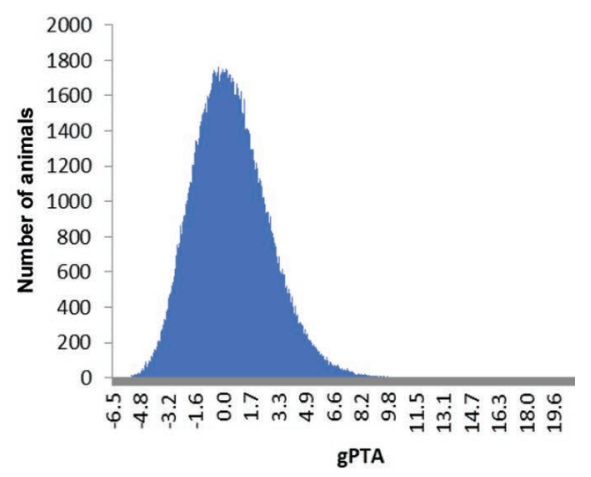

Figure 4. Distribution of genomic (g)PTA for calf respiratory disorders (a), scours (b), and calf livability (c) for all genotyped animals.

\section{Correlations of Calf Wellness Genomic PTA with Those for Other Economically Relevant Traits}

To check associations among the calf wellness traits and with the genomic (g)PTA for other traits in the Zoetis and the national genetic evaluations, genetic correlations were approximated using method by Calo et al. (1973), as described in Parker Gaddis et al. (2014):

$$
\hat{r}_{g_{1,2}}=\frac{\sqrt{\left(\sum_{i=1}^{n} R E L_{1 i}\right)\left(\sum_{i=1}^{n} R E L_{2 i}\right)}}{\sum_{i=1}^{n}\left(R E L_{1 i} \times R E L_{2 i}\right)} \times r_{1,2},
$$

where $\hat{r}_{g_{1,2}}$ is the approximated genetic correlation between traits 1 and 2, $R E L_{1 i}$ and $R E L_{2 i}$ are reliabilities of (g)PTA for trait 1 and 2, respectively, for animal $i$, and $r_{1,2}$ is the Pearson (product-moment) correlation between (g)PTA for traits 1 and 2. The standard error of the approximate genetic correlation was calculated following Sokal and Rohlf (1995), as described in Parker
Gaddis et al. (2014). Only (g)PTA of animals having values of the diagonal of the genomic relationship matrix within mean \pm 3 standard deviations (SD) were used in this calculation.

\section{RESULTS AND DISCUSSION}

\section{Number of Records and Incidence of Calf Health Disorders}

Table 1 shows the number of records used in genetic evaluation and the incidence (percent of affected animals in the data) for each trait. The numbers of records varied depending on the trait. The variation was caused by differences in herds recording various traits and the implementation of the "opportunity period" for each trait. Although most herds recorded death events, not all herds recorded respiratory events and scours with the same precision.

The incidence of RESP for the entire period of 0 to $365 \mathrm{~d}$ of age was $21 \%$. The highest incidence of all a)

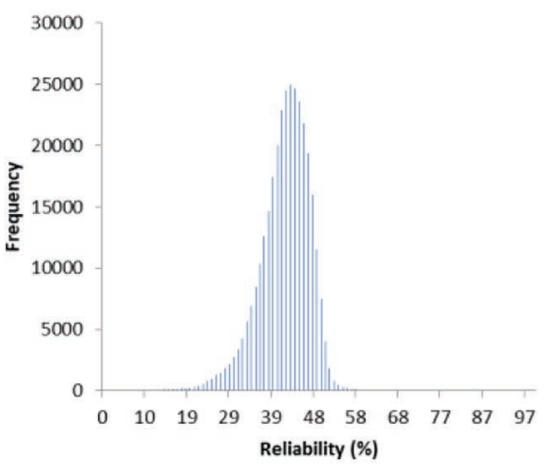

b)

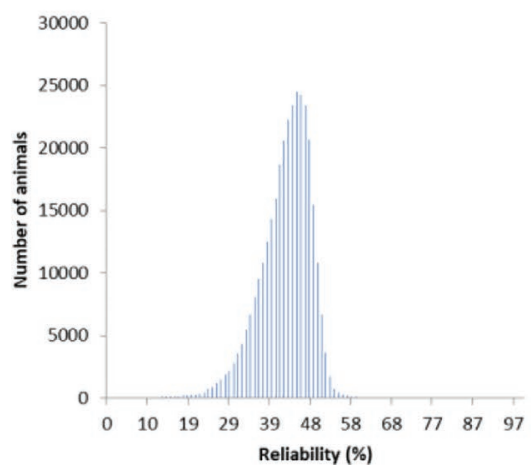

c)

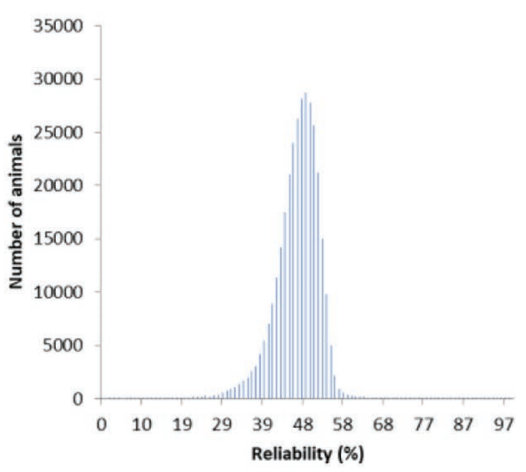

Figure 5. Distribution of reliabilities for calf respiratory disorders (a), scours (b), and calf livability (c) for all genotyped animals. 
Table 5. Mean, SD, minima, and maxima of genomic PTA for calf wellness traits for genotyped animals (N) born between 2015 and 2018 and without phenotypic records or progeny

\begin{tabular}{lccccc}
\hline Trait $^{1}$ & $\mathrm{~N}$ & Mean & SD & Minima & Maxima \\
\hline RESP & 130,344 & 2.528 & 3.144 & -7.728 & 18.646 \\
DIAR & 120,366 & 0.249 & 3.287 & -9.628 & 17.723 \\
DEAD & 121,642 & 0.209 & 2.110 & -6.172 & 12.577 \\
\hline
\end{tabular}

${ }^{1} \mathrm{RESP}=$ calf respiratory disease DIAR $=$ calf scours; DEAD $=$ calf livability.

traits in this analysis was found for DIAR, at $26.1 \%$. The incidence of deaths between 2 and $365 \mathrm{~d}$ of age was $4.7 \%$. For all traits, the incidence found in our data was lower than that reported in the literature, which might be associated with the fact that the producers who provided the data were above average in herd management and disease control.

\section{Variance Components}

Table 2 shows estimates for genetic, herd $\times$ year, and residual variance, heritabilities, and their standard errors, and the adjusted values of variance components used in BLUPF90 programs (cblup90iod2 and accf90GS).

The heritabilities for the calf wellness traits, estimated on the liability scale, were $0.042,0.045$, and 0.060 for RESP, DIAR, and DEAD, respectively. The heritability estimates for RESP and DIAR were comparable with values published in the literature (e.g., Henderson et al., 2011; McCorquodale et al., 2013).

The estimated heritability of 0.060 for DEAD was higher than the heritability of the comparable trait "heifer livability" (defined as a survival of an animal between $5 \mathrm{~d}$ and 18 mo of age), which wass estimated by the Council on Dairy Cattle Breeding (CDCB, Bowie, MD) at 0.004 (Norman, 2016). The reason for higher heritabilities in our analyses relative to $\mathrm{CDCB}$ results could not be associated with a single factor, considering that the data used in this study may differ in geographical distribution, data size, trait definition, and model used.

\section{Genomic Evaluation}

The number of rounds needed for convergence varied by trait, ranging from 16 for DEAD to 43 for DIAR. It is in the interest of computation time to reach the convergence in the fewest possible rounds; however, fewer than 10 iterations is not recommended because of the poorer estimation of the threshold (Shogo Tsuruta, Department of Animal and Dairy Science, University of Georgia, Athens, personal communication). It ap-
Table 6. Mean, SD, minima, and maxima of reliabilities for calf wellness traits for genotyped animals (N) born between 2015 and 2018 and without phenotypic records or progeny

\begin{tabular}{lccccc}
\hline Trait $^{1}$ & $\mathrm{~N}$ & Mean & SD & Minima & Maxima \\
\hline RESP & 130,344 & 0.41 & 0.050 & 0.12 & 0.58 \\
DIAR & 120,366 & 0.42 & 0.051 & 0.13 & 0.60 \\
DEAD & 121,642 & 0.46 & 0.044 & 0.17 & 0.62 \\
\hline
\end{tabular}

${ }^{1} \mathrm{RESP}=$ calf respiratory disease DIAR $=$ calf scours; $\mathrm{DEAD}=$ calf livability.

pears that the number of iteration rounds was inversely proportional to the number of records (fewer records $=$ more iteration rounds) but also the incidence of the disorder (lower incidence needs more iterations). We expect the convergence for RESP and DIAR to improve in the future because the number of phenotypic records will increase.

\section{gPTA and Reliabilities}

The results regarding gPTA and reliabilities are shown only for animals with values of the diagonal of the genomic relationship matrix $\left(\mathbf{G}_{-} \mathbf{d i a g}\right)$ within \pm 3 SD from the mean $(1.006 \pm 0.12)$. Because the $\mathbf{G}$ matrix was scaled using average allele frequencies (VanRaden, 2008), animals having genotypes very different from the overall population's genomic profile (because they originated from a different population or were highly inbred) had extreme values of G_diag (Simeone et al., 2012). As a result of applying the approximation formula, these animals had extremely low reliabilities. From the initial 325,025 animals with genotypes, 3,493 had values of G_diag beyond the mean \pm 3 SD.

Tables 3 and 4 show means, standard deviations, minima, and maxima for gPTA and reliabilities, respectively, for calf wellness traits for all genotyped animals in the analysis with values of $G$ _diag within the mean $\pm 3 \mathrm{SD}$. The average values, SD, and extreme values of gPTA for calf wellness traits were comparable to those for wellness traits in dairy cows (Vukasinovic et al., 2017). The distribution of gPTA for RESP, DIAR, and DEAD for all genotyped animals is given in Figure 4. The average reliabilities of calf wellness traits were

Table 7. Mean, SD, minima, and maxima of genomic PTA for calf wellness traits for genotyped bulls $(\mathrm{N})$ with at least 100 phenotyped progeny

\begin{tabular}{lrrrrc}
\hline Trait $^{1}$ & \multicolumn{1}{c}{$\mathrm{N}$} & Mean & SD & Minima & Maxima \\
\hline RESP & 788 & 3.53 & 4.78 & -7.7 & 24.0 \\
DIAR & 438 & 3.02 & 6.28 & -11.5 & 28.5 \\
DEAD & 1,029 & 2.24 & 3.14 & -4.9 & 22.8 \\
\hline
\end{tabular}

${ }^{1} \mathrm{RESP}=$ calf respiratory disease DIAR $=$ calf scours; DEAD $=$ calf livability. 
Table 8. Mean, SD, minima, and maxima of reliabilities for calf wellness traits for genotyped bulls $(\mathrm{N})$ with at least 100 phenotyped progeny

\begin{tabular}{lrrrcc}
\hline Trait $^{1}$ & N & Mean & SD & Minima & Maxima \\
\hline RESP & 788 & 0.868 & 0.066 & 0.719 & 0.992 \\
DIAR & 438 & 0.872 & 0.058 & 0.756 & 0.987 \\
DEAD & 1,029 & 0.893 & 0.059 & 0.745 & 0.994 \\
\hline
\end{tabular}

${ }^{1} \mathrm{RESP}=$ calf respiratory disease; DIAR $=$ calf scours; DEAD $=$ calf livability.

lower than those reported for Zoetis dairy wellness traits, reflecting their lower estimated heritabilities and the smaller amount of information currently available. The average reliabilities were $42 \%$ for RESP, $43 \%$ for DIAR, and $47 \%$ for DEAD. All traits showed consistent SD of about 6 percentage points, with extremes reaching 19 and $99 \%$. Figure 5 shows the distribution of reliabilities for RESP, DIAR, and DEAD. Most animals had reliabilities between about 40 and $45 \%$, with only 175 animals having reliabilities of $90 \%$ or higher. All of the high-reliability animals were genotyped bulls with more than 300 phenotyped daughters each.

Tables 5 and 6 show means, SD, minima, and maxima for gPTA and reliabilities, respectively, for calf wellness traits for young genotyped Holstein animals without phenotype or progeny. The means, SD, and extremes showed very similar values as the entire set of genotyped animals, simply because young genotyped animals made up the majority of the genotyped animals for all traits. The average reliabilities of gPTA for calf wellness traits for young genotyped animals exceeded $40 \%$ for all traits, with the maximum reaching $62 \%$ for well-connected animals; that is, fully pedigreed animals having many ancestors and relatives with phenotypes and genotypes.

Tables 7 and 8 show means, SD, minima, and maxima for gPTA and reliabilities, respectively, for calf wellness traits for genotyped bulls having at least 100 progeny with phenotypes in the genetic evaluation. This category contained animals showing extreme values for RESP and DIAR. The bulls with the highest (worst) gPTA had large proportions of progeny with a given disorder, which influenced their gPTA. They had $50.4,29.2$, and $14.1 \%$ of their progeny sick, of the total of 434,511 , and 769 phenotyped progeny for RESP,
Table 9. Approximated genetic correlations (SE in parentheses) among calf wellness traits

\begin{tabular}{lcc}
\hline Trait $^{1}$ & DIAR & DEAD \\
\hline RESP & $0.555(0.002)$ & $0.697(0.001)$ \\
DIAR & $0.464(0.002)$ \\
\hline${ }^{1}$ RESP = calf respiratory disease; DIAR = calf scours; DEAD = calf \\
livability.
\end{tabular}

DIAR, and DEAD, respectively; the bull with the lowest (best) gPTA for DIAR had only $2.5 \%$ affected offspring (data not shown). The reliabilities for all traits were high because of the large number of progeny with phenotypes required for the analysis. On average, the reliabilities were higher for traits with higher heritabilities and more information available (more progeny with phenotypic data).

\section{Genetic Correlations}

Genetic Correlations Among Calf Wellness Traits. Table 9 shows correlations (product-moment correlations and approximated genetic correlations) among calf wellness traits. The approximated genetic correlations among calf wellness traits were all positive in sign and moderate in magnitude, ranging from 0.46 between DIAR and DEAD to 0.70 between RESP and DEAD. This indicated that animals that suffer from one disease are more likely to get another disease or die. A lower genetic correlation (0.29) was described in German Holstein in animals up to 2 mo of age between DIAR and RESP (Mahmoud et al., 2017); DIAR is strongly associated with RESP because of the impact that both have on the weight and subsequent recovery of the animal under treatment (Lundborg et al., 2003; McCorquodale et al., 2013).

Genetic Correlations with Zoetis Dairy Wellness Traits. Table 10 shows approximated genetic correlations between calf wellness traits and Zoetis dairy wellness traits that are part of the Clarifide Plus product (Di Croce et al., 2016). The approximated genetic correlations with all dairy wellness traits were low or close to zero. Most correlations with DIAR and DEAD were positive, which was expected. The correlations with RESP were mostly negative, but low in

Table 10. Approximated genetic correlations (SE in parentheses) of calf wellness traits with Zoetis (Kalamazoo, MI) dairy wellness traits ${ }^{1}$

\begin{tabular}{lcrrrrr}
\hline Trait & MAST & \multicolumn{1}{c}{ METR } & \multicolumn{1}{c}{ RETP } & \multicolumn{2}{c}{ DA } & \multicolumn{2}{c}{ KETO } \\
\hline RESP & $0.000(0.002)$ & $-0.052(0.002)$ & $0.078(0.002)$ & $-0.150(0.002)$ & $-0.159(0.002)$ & $0.002(0.002)$ \\
DIAR & $0.080(0.002)$ & $0.077(0.002)$ & $0.023(0.002)$ & $-0.058(0.002)$ & $0.241(0.002)$ & $-0.093(0.002)$ \\
DEAD & $0.244(0.002)$ & $0.176(0.002)$ & $0.157(0.002)$ & $0.099(0.002)$ & $0.097(0.002)$ & $0.158(0.002)$ \\
\hline
\end{tabular}

${ }^{1} \mathrm{RESP}=$ calf respiratory disease DIAR $=$ calf scours; DEAD = calf livability; MAST = mastitis; METR = metritis; RETP $=$ retained placenta; $\mathrm{DA}=$ displaced abomasum; KETO = ketosis; LAME = lameness. 
magnitude. Positive correlations with DIAR suggested that animals susceptible to calfhood diseases may show increased incidence of disorders later in production. The highest positive correlations were observed between DEAD and MAST and between DIAR and KETO (r $\sim 0.24$ ). The correlations with mortality traits were estimated solely through genetic relationships, because animals with positive mortality phenotypes did not live long enough to have dairy wellness trait phenotypes.

Similar low correlations were found between calf diseases and disease occurrences of first-lactation German Holstein cows (Mahmoud et al., 2017). In agreement with that report, our results imply that calf diseases are poor predictors of cows' health. Therefore, it is valuable to have both calf and cow health trait genomic predictions for selection.

Genetic Correlations with Traits in the US National Genetic Evaluation. Table 11 shows approximated genetic correlations among calf wellness traits and the traits in the US national genetic evaluation provided by CDCB. The trait DIAR was negatively associated with net merit $(\mathrm{NM} \$)$, milk and protein yield, productive life, daughter pregnancy rate (DPR), cow conception rate (CCR), type (PTAT), and livability, and positively with SCS and daughter calving ease (DCE) and daughter stillbirth (DSB). These correlations make sense biologically, indicating that animals suffering from scours early in life end up being less profitable and less fertile, having more calving difficulties, a shorter productive life, and a higher risk of dying. Similarly, DEAD was negatively correlated with NM\$, DPR, productive life (PL), CCR, heifer conception rate (HCR), and livability, and positively correlated with SCS and DCE and DSB; however, correlations with yield traits and type were close to zero. Multiple studies have found that animals suffering from calfhood diseases end up being less productive and having shorter herd life even if they recover (e.g., Rossini, 2004; Dunn et al., 2018). Surprisingly, correlations of RESP with most CDCB traits were in the opposite directions. Similar correlations between bovine respiratory disease (BRD) in calves and reproduction traits were found by Henderson et al. (2011) in a population of Holstein calves from New York. In a review study targeting influence of BRD on animals' survival and performance in the Netherlands, Van Der Fels-Klerx et al. (2002) concluded that "although several associations were found, the data on the majority of the potential productivity effects and risk factors of BRD are ambiguous or incomplete." The favorable correlations in this study between RESP and the traits in the national genetic evaluation may be simply linked to the nature of our data, suggesting that herds with higher production levels had more complete recording of RESP events.

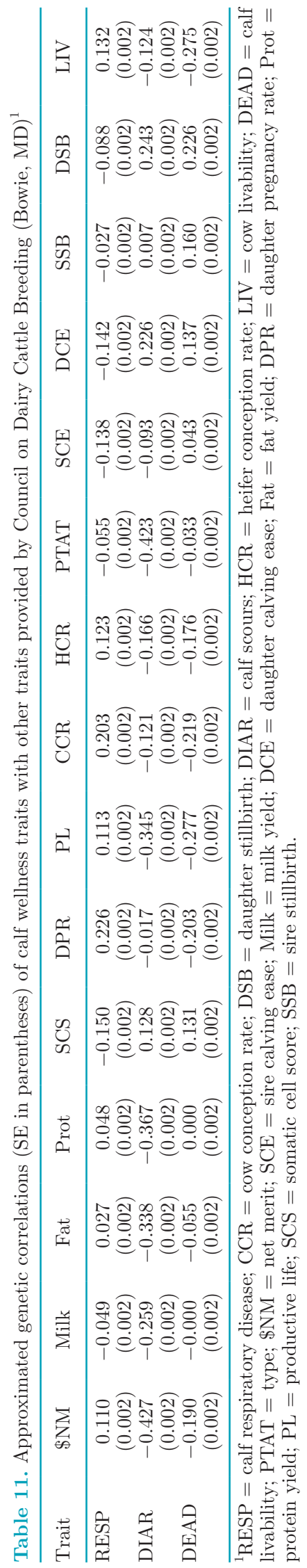

Journal of Dairy Science Vol. 102 No. 3, 2019 


\section{CONCLUSIONS}

Genomic evaluation for calf wellness traits based on producer-recorded data was developed and successfully run with 325,025 genotypes. The estimated heritabilities of calf wellness traits were comparable with those reported in the literature. Large numbers of records result in high reliabilities even for traits with low heritabilities, showing that selection of animals for calf wellness traits can be feasible and potentially contribute to the genetic progress. A validation study may be conducted in the future to evaluate the accuracy and bias of ssGBLUP. Genetic correlations among calf wellness traits were all positive, likely implying that they are controlled by the overall immune system of the calf. Genetic correlations with Zoetis dairy wellness traits were low but mostly positive, indicating that animals suffering from early disorders may show poorer health later in life. Genetic correlations between calf wellness and routinely evaluated traits provided by the Council on Dairy Cattle Breeding were relatively low and in the expected direction for most traits. Having calf health disorders, especially scours, early in life negatively affects future profitability of animals, which is another reason to invest into genetic improvement of calf health.

\section{REFERENCES}

Aguilar, I., I. Misztal, D. L. Johnson, A. Legarra, S. Tsuruta, and T. J. Lawlor. 2010. A unified approach to utilize phenotypic, full pedigree, and genomic information for genetic evaluation of Holstein final score. J. Dairy Sci. 93:743-752.

Aguilar, I., I. Misztal, S. Tsuruta, A. Legarra, and H. Wang. 2014. PREGSF90 - POSTGSF90: Computational tools for the implementation of single-step genomic selection and genome-wide association with ungenotyped individuals in BLUPF90 programs. Page 680 in Proc. World Congr. Genet. Appl. Livest. Prod., Vancouver, Canada, 17-22 Aug. 2014. Accessed Dec. 21, 2018. https://www .asas.org/docs/default-source/wcgalp-posters/680_paper_9756 _manuscript_1666_0.pdf?sfvrsn=2.

Calo, L. L., R. E. McDowell, L. D. Van Vleck, and P. D. Miller. 1973. Genetic aspects of beef production among Holstein-Friesians pedigree selected for milk production. J. Anim. Sci. 37:676-682.

Di Croce, F., A. McNeel, B. Reiter, and J. Osterstock. 2016. Building a healthier herd with CLARIFIDE ${ }^{\oplus}$ Plus. Zoetis Technical Bulletin, March 1, 2016. Accessed Oct. 18, 2018. https://www.zoetisus .com/animal-genetics/media/documents/clarifide-resources/ wellness-trait-technical-bulletin_final_022316.pdf.

Dunn, T. R., T. L. Ollivett, D. L. Renaud, K. E. Leslie, S. J. LeBlanc, T. F. Duffield, and D. F. Kelton. 2018. The effect of lung consolidation, as determined by ultrasonography, on first-lactation milk production in Holstein dairy calves. J. Dairy Sci. 101:5404-5410.

Fragomeni, B.O., D. A. L. Lourenco, S. Tsuruta, Y. Masuda, I. Aguilar, A. Legarra, T. J. Lawlor, and I. Misztal. 2015. Hot topic: Use of genomic recursions in single-step genomic best linear unbiased predictor (BLUP) with a large number of genotypes. J. Dairy Sci. 98:4090-4094.

Gilmour, A. R., B. J. Gogel, B. R. Cullis, S. J. Welham, and R. Thompson. 2015. ASReml User Guide Release 4.1 Structural Specification, VSN International Ltd., Hemel Hempstead, UK. www .vsni.co.uk.
Gonzalez-Pena, D., B. R. Southey, P. J. Pinedo, J. J. Brooker, J. E. P. Santos, G. M. Schuenemann, G. J. M. Rosa, R. Gilbert, R. Bicalho, R. Chebel, K. Galvao, C. Seabury, J. Fetrow, W. W. Thatcher, and S. L. Rodriguez-Zas. 2018. Genome-wide association mapping of loci associated with ovarian cyclicity and pregnancy in dairy cattle. Page 353 in Proc. World Congr. Genet. Appl. Livest. Prod., Auckland, New Zealand, 11-16 Feb. 2018. Accessed Dec. 21, 2018. https://az659834.vo.msecnd.net/eventsairaueprod/production -innovators-public/132513259d4c403992118b5f44b9aa91.

Gulliksen, S. M., K. I. Lie, and O. Østerås. 2009. Calf health monitoring in Norwegian dairy herds. J. Dairy Sci. 92:1660-1669.

Hansen, M., P. Madsen, J. Jensen, J. Pedersen, and L. G. Christensen. 2003. Genetic parameters of postnatal mortality in Danish Holstein calves. J. Dairy Sci. 86:1807-1817.

Henderson, L., F. Miglior, A. Sewalem, J. Wormuth, D. Kelton, A. Robinson, and K. E. Leslie. 2011. Short communication: Genetic parameters for measures of calf health in a population of Holstein calves in New York State. J. Dairy Sci. 94:6181-6187.

Heringstad, B., Y. M. Chang, D. Gianola, and O. Østerås. 2008. Short communication: Genetic analysis of respiratory disease in Norwegian Red calves. J. Dairy Sci. 91:367-370.

Hulbert, L. E., and S. J. Moisá. 2016. Stress, immunity, and the management of calves. J. Dairy Sci. 99:3199-3216.

Legarra, A., I. Aguilar, and I. Misztal. 2009. A relationship matrix including full pedigree and genomic information. J. Dairy Sci. 92:4656-4663.

Lundborg, G. K., P. A. Oltenacu, D. O. Maizon, E. C. Svensson, and P. G. A. Liberg. 2003. Dam-related effects on heart girth at birth, morbidity and growth rate from birth to 90 days of age in Swedish dairy calves. Prev. Vet. Med. 60:175-190.

Mahmoud, M., T. Yin, K. Brügemann, and S. König. 2017. Phenotypic, genetic, and single nucleotide polymorphism marker associations between calf diseases and subsequent performance and disease occurrences of first-lactation German Holstein cows. J. Dairy Sci. 100:2017-2031.

Masuda, Y., I. Misztal, S. Tsuruta, A. Legarra, I. Aguilar, D. A. L. Lourenco, B. O. Fragomeni, and T. J. Lawlor. 2016. Implementation of genomic recursions in single-step genomic best linear unbiased predictor for US Holsteins with a large number of genotyped animals. J. Dairy Sci. 99:1968-1974.

McCorquodale, C. E., A. Sewalem, F. Miglior, D. Kelton, A. Robinson, A. Koeck, and K. E. Leslie. 2013. Short communication: Analysis of health and survival in a population of Ontario Holstein heifer calves. J. Dairy Sci. 96:1880-1885.

Misztal, I. 2005. Problems with the threshold model. Accessed Sep. 26, 2017. http://nce.ads.uga.edu/ ignacy/numpub/blupf90/winbin/ zs6/Readme.threshold_model.

Misztal, I., I. Aguilar, A. Legarra, and T. J. Lawlor. 2010. Choice of parameters for single-step genomic evaluation for type. J. Dairy Sci. 93(Suppl. 1):166. (Abstr.)

Misztal, I., A. Legarra, and I. Aguilar. 2014a. Using recursion to compute the inverse of the genomic relationship matrix. J. Dairy Sci. 97:3943-3952.

Misztal, I., S. Tsuruta, D. Lourenco, I. Aguilar, A. Leggara, and Z. Vitezica. 2014b. Manual for BLUPF90 family of programs. Accessed Jul. 27, 2016. http://nce.ads.uga.edu/wiki/lib/exe/fetch .php?media=blupf90_all4.pdf.

Misztal, I., S. Tsuruta, T. Strabel, B. Auvray, and T. Druet. 2002. BLUPF90 and related programs (BGF90). Page 743 in Proc. World Congr. Genet. Appl. Livest. Prod., Montpellier, France. Editions Quae, Montpellier, France.

Misztal, I., Z. G. Vitezica, A. Legarra, I. Aguilar, and A. A. Swan. 2013. Unknown-parent groups in single-step genomic evaluation. J. Anim. Breed. Genet. 130:252-258.

Mohd Nor, N. H., W. Steeneveld, M. C. Mourits, and H. Hogeveen. 2012. Estimating the costs of rearing young dairy cattle in the Netherlands using a simulation model that accounts for uncertainty related to diseases. Prev. Vet. Med. 106:214-224.

Murray, B. 2011. Optimizing calf survival at birth. Ontario Ministry of Agriculture, Food, and Rural Affairs. Accessed Sep. 26, 2017. http: 
//www.omafra.gov.on.ca/english/livestock/dairy/facts/optbirth .htm.

Neibergs, H. L., C. M. Seabury, A. J. Wojtowicz, Z. Wang, E. Scraggs, J. N. Kiser, M. Neupane, J. E. Womack, A. Van Eenennaam, G. R. Hagevoort, T. W. Lehenbauer, S. Aly, J. Davis, and J. F. Taylor., and The Bovine Respiratory Disease Complex Coordinated Agricultural Project Research Team. 2014. Susceptibility loci revealed for bovine respiratory disease complex in pre-weaned Holstein calves. BMC Genomics 15:1164.

Norman, D. 2016. Cow Livability Evaluation and Heifer Livability Research. CDCB Industry Meeting, October 2016. Accessed Sep. 26, 2017. https://aipl.arsusda.gov/publish/presentations/CDCB16/ WDE\%20Cow\%20Livability\%20Final.pptx.

Parker Gaddis, K. L., J. B. Cole, J. S. Clay, and C. Maltecca. 2014. Genomic selection for producer-recorded health event data in US dairy cattle. J. Dairy Sci. 97:3190-3199.

Pocrnic, I., D. A. L. Lourenco, Y. Masuda, and I. Misztal. 2016. Dimensionality of genomic information and performance of the Algorithm for Proven and Young for different livestock species. Genet. Sel. Evol. 48:82.

Poulsen, K. P., and S. M. McGuirk. 2009. Respiratory disease of the bovine neonate. Vet. Clin. North Am. Food Anim. Pract. 25:121137.

Rossini, K. 2004. Effects of calfhood respiratory and digestive disease on calfhood morbidity and first lactation production and survival rates. MS Thesis. Dairy Science Department, Virginia Tech, Blacksburg, VA.

Sargolzaei, M., J. P. Chesnais, and F. S. Schenkel. 2011. FImpute: An efficient imputation algorithm for dairy cattle populations. J. Dairy Sci. 94(E-Suppl. 1):421. (Abstr.)

Simeone, R., I. Misztal, I. Aguilar, and Z. Vitezica. 2012. Evaluation of a multi-line broiler chicken population using a single-step genomic evaluation procedure. J. Anim. Breed. Genet. 129:3-10.

Sischo, W. M., D. W. Hird, I. A. Gardner, W. W. Utterback, K. H. Christiansen, T. E. Carpenter, and R. Heron. 1990. Economics of disease occurrence and prevention on California dairy farms: A report and evaluation of data collected for the national animal health monitoring system, 1986-87. Prev. Vet. Med. 8:141-156.

Sokal, R. R., and F. J. Rohlf. 1995. Biometry: The Principles and Practice of Statistics in Biological Research. 3rd ed. W. H. Freeman, New York, NY.

Tsuruta, S., D. Lourenco, Y. Masuda, D. W. Moser, and I. Misztal. 2016. Practical approximation of accuracy in genomic breeding values for a large number of genotyped animals. J. Anim. Sci. 94:162.

Van Der Fels-Klerx, H. J., S. W. Martin, M. Nielsen, and R. B. M. Huirne. 2002. Effects on productivity and risk factors of bovine respiratory disease in dairy heifers; a review for the Netherlands. Neth. J. Agric. Sci. 50:27-45.

VanRaden, P. M. 2008. Efficient methods to compute genomic predictions. J. Dairy Sci. 91:4414-4423.

VanRaden, P. M., A. H. Sanders, M. E. Tooker, R. H. Miller, H. D. Norman, M. T. Kuhn, and G. R. Wiggans. 2004. Development of a national genetic evaluation for cow fertility. J. Dairy Sci. 87:2285-2292.

Vukasinovic, N., N. Bacciu, C. A. Przybyla, P. Boddhireddy, and S. K. DeNise. 2017. Development of genetic and genomic evaluation for wellness traits in US Holstein cows. J. Dairy Sci. 100:428-438.

Wiggans, G. R., T. S. Sonstegard, P. M. VanRaden, L. K. Matukumalli, R. D. Schnabel, J. F. Taylor, F. S. Schenkel, and C. P. Van Tassell. 2009. Selection of single-nucleotide polymorphisms and quality of genotypes used in genomic evaluation of dairy cattle in the United States and Canada. J. Dairy Sci. 92:3431-3436.

Zwald, N. R., K. A. Weigel, Y. M. Chang, R. D. Weper, and J. S. Clay 2004. Genetic selection for health traits using producer-recorded data. I. Incidence rates, heritability estimates, and sire breeding values. J. Dairy Sci. 87:4287-4294. 